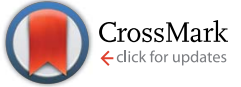

Cite this: RSC Adv., 2017, 7, 16505

Received 6th December 2016 Accepted 3rd February 2017

DOI: 10.1039/c6ra27836a

rsc.li/rsc-advances

\section{Enhanced capacity and cycle life of nitrogen-doped activated charcoal anode for the lithium ion battery: a solvent-free approach $\uparrow$}

\author{
Chandrasekar M. Subramaniyam, ${ }^{\text {ab }}$ N. R. Srinivasan, ${ }^{c}$ Zhixin Tai, $^{a}$ Hua Kun Liu ${ }^{\star a}$ \\ and Shi Xue Dou ${ }^{a}$
}

Herein, we investigated the electrochemical performance of nitrogen-doped commercial activated charcoal (R-AC) for lithium-ion batteries (LIBS). With this aim, nitrogen was doped into R-AC via a solvent-free approach, which involved annealing R-AC under $\mathrm{N}_{2}$ and $\mathrm{NH}_{3}$ atmospheres at $800{ }^{\circ} \mathrm{C}$, and the product was tested as an anode for LIBs. The sample annealed under an $\mathrm{NH}_{3}$ atmosphere (NH-AC) had a nitrogen doping level of 4.7 at\% with a specific surface area of $894.5 \mathrm{~m}^{2} \mathrm{~g}^{-1}$ and a reduced O/C ratio of 0.31 in comparison to the sample annealed under an $\mathrm{N}_{2}$ atmosphere $(\mathrm{N}-\mathrm{AC}$ ) and R-AC. Raman spectroscopy detected disorder/defects owing to the introduction of various $\mathrm{C}-\mathrm{N}-\mathrm{C}$ terminal bonds on the surface of R-AC, which significantly improved the electrical conductivity of both $\mathrm{N}-\mathrm{AC}$ and $\mathrm{NH}-\mathrm{AC}$. Therefore, endowed with these physicochemical properties, $\mathrm{NH}-\mathrm{AC}$ delivered a high specific capacity of $736.4 \mathrm{~mA} \mathrm{~h} \mathrm{~g}^{-1}$ at $50 \mathrm{~mA} \mathrm{~g}^{-1}$ (up to 150 cycles) and $524 \mathrm{~mA} \mathrm{~h} \mathrm{~g}^{-1}$ at $200 \mathrm{~mA} \mathrm{~g}^{-1}$ even after 500 cycles, which indicates much better performance in comparison to those of R-AC, N-AC and commercial graphite. This remarkable electrochemical performance of $\mathrm{NH}-\mathrm{AC}$ can be attributed to the synergistic effect of its large specific surface area, disordered graphitic structure, and low charge transfer resistance, which enable it to act as an anode for high-performance LIBs.

\section{Introduction}

In recent years, the market for electrochemical storage devices has rapidly increased to reduce our dependence on fossil fuels, which are needed to operate most transportation systems. Among all energy storage devices, the lithium-ion battery (LIB) is the most promising owing to its high gravimetric energy density, high power density, and low self-discharge rate. Ever since its commercialization by Sony Inc. In the 1990s, it has revolutionized the market for portable electronic devices and is therefore considered to be the most likely eco-friendly candidate for powering electric vehicles (EV)/plug-in EVs and providing off-grid energy storage to eliminate power transmission losses. ${ }^{1-3}$ In commercial lithium-ion batteries (LIBs), graphite is used as the anode and is still preferred in spite of the enormous progress made in high-energy alloying and conversion-based materials., ${ }^{4,5}$ This is mainly due to the numerous merits of graphite, despite its

Institute for Superconducting and Electronic Materials, Australian Institute for Innovative Materials, University of Wollongong, Innovation Campus, North Wollongong, NSW 2500, Australia. E-mail: hua@uow.edu.au

${ }^{b}$ Texas Materials Institute, Department of Mechanical Engineering, University of Texas Austin, 204 E Dean Keeton St., C2200, Austin, Texas 78712, USA

'Department of Chemical Engineering, Indian Institute of Technology Madras, Chennai 600036, India

$\dagger$ Electronic supplementary information (ESI) available. See DOI: $10.1039 / \mathrm{c} 6 \mathrm{ra} 27836 \mathrm{a}$ demerits, such as low reversible specific capacity and rate performance, which limit the use of present state-of-the-art electrodes for large-scale energy storage applications. ${ }^{6,7}$ Therefore, carbon-based anode materials that exhibit excellent reversible specific capacity and cycling performance are required for the abovementioned applications.

The mechanism of intercalation and deintercalation of lithium with carbonaceous materials could be expressed as $6 \mathrm{C}+$ $y \mathrm{Li}^{+}+x \mathrm{e}^{-}=\mathrm{Li}_{y} \mathrm{C}_{6}$, in which $y$ is the stoichiometric factor, where $y=1$ for graphitic carbon and $0.5<y<3$ for low-temperatureannealed non-graphitic carbon. ${ }^{8}$ Although the latter displays a high specific capacity, it also suffers from large irreversible capacity losses in the first cycle owing to decomposition of the electrolyte and the formation of a solid-electrolyte interphase (SEI) over its surface at an operating voltage close to that of lithium. It traps a large amount of lithium ions in its network during intercalation owing to oxygen-containing surface functional groups or diffusion constraints. ${ }^{9}$ Even so, the initially formed SEI layer prevents further decomposition of the electrolyte at the anode surface and reduces the diffusivity of charge carriers between the anode and the electrolyte. Therefore, the thickness of the SEI layer could be adjusted by tailoring the properties of carbon and the surface functional groups. Numerous strategies are used to mitigate the formation of an SEI by tuning its morphology, such as the use of graphene, carbon nanotubes, carbon nanofibers, and porous carbon. ${ }^{10}$ 
Nanostructured porous carbons are of great interest as they provide enhanced reversible lithium storage and excellent cycling life. This is achieved because of their large electrodeelectrolyte interface, which promotes the charge transfer reaction by reducing the diffusion length of lithium. Another approach comprises the modification of their surface functional groups with non-carbon elements such as nitrogen, sulphur, and phosphorus. ${ }^{11,12}$ The presence of heteroatoms enhances the reactivity and electrical conductivity and thereby increases the lithium storage capacity. ${ }^{13}$ In addition to these advantages, amorphous carbon also displays high mechanical stability against the volumetric changes that occur during the insertion and deinsertion of lithium. Hence, surface-modified nanostructured carbon provides an excellent network for interstitial connections, which results in superior electrochemical performance, and also acts as a buffering agent for mechanically weak inorganic electrode materials. ${ }^{9}$

Because commercial activated charcoal (R-AC) possesses a large specific surface area $\left(>500 \mathrm{~m}^{2} \mathrm{~g}^{-1}\right)$ and pore volume $(0.8$ $\mathrm{cm}^{3} \mathrm{~g}^{-1}$ ), it is widely used in supercapacitors and also finds applications in the areas of hydrogen storage, water treatment, and separation techniques. ${ }^{\mathbf{1 0 , 1 4}}$ As mentioned earlier, the introduction of nitrogen heteroatoms into carbon leads to the modification of its surface with functional groups, which further enhances its electrochemical performance with respect to $\mathrm{Li}^{+} / \mathrm{Li}^{0}$. Multiple ways of introducing $\mathrm{N}$ atoms have been investigated in recent years ${ }^{\mathbf{1 0}}$ using nitric acid and melamine as $\mathrm{N}$ sources. These chemical precursors tend to give rise to a low nitrogen percentage with morphological changes and also leave unreacted chemicals/inactive species in the product, which impede its electrochemical performance. With this aim, a solvent-free inexpensive method has been chosen in this study for doping heteroatoms into commercial activated carbon (AC) to understand the behaviour of the electrode during the cycling process in LIBs. The selection of R-AC as the anode was based on its commercial availability at a low cost in comparison to that of conventional graphite.

\section{Results and discussion}

The XRD patterns of R-AC, N-AC, and NH-AC are shown in Fig. 1a. Distinct peaks are observed together with broad peaks in the $2 \theta$ ranges of $20-25^{\circ}$ and $42-45^{\circ}$, which could be due to the reflections of the (002) and (100) planes, respectively. ${ }^{15}$ In addition, there was a slight shift of $0.15^{\circ}$ in $2 \theta$ towards higher angles and the peaks were broadened as a result of annealing under $\mathrm{N}_{2}$ and $\mathrm{NH}_{3}$ gases, which confirms the presence of amorphous carbon. More importantly, the shift in $2 \theta$ values could be due to an increase in the interlayer spacing between the (002) planes of graphite in terms of Bragg's equation. Moreover, the degree of graphitization of all the samples was found to be $1.98 \pm 0.03$, which was measured using an empirical parameter $(R)$ and indicates that treatment with $\mathrm{N}_{2}$ or $\mathrm{NH}_{3}$ gas did not significantly alter the graphitic structure. The parameter $R$ is defined as the ratio of the height of the (002) Bragg peak to its background. ${ }^{16}$ The value of $R$ for soft carbon is 1.5 , which is lower than that for hard carbon samples. The high value of $R$ indicates the presence of a well-developed (highly crystalline) graphitic structure. Furthermore, it can be seen that there are very small sharp peaks in the XRD patterns, which may be due to $\mathrm{SiO}_{2}$. These $\mathrm{SiO}_{2}$ peaks would have originated from the sources that were used for the preparation of activated charcoal. The $\mathrm{SiO}_{2}$ commonly used sources of activated charcoal are coal, wood, and coconut shell. For example, coconut shell is an agricultural product, and its major and minor constituents are cellulose, lignin, pentosans, and silica, respectively. Therefore, commercial activated charcoal contains $12 \mathrm{wt} \%$ non-carbonaceous materials (including silica), as deduced from thermogravimetric analysis (TGA, Fig. S1 $\dagger$ ), which result in a peak in the XRD pattern. ${ }^{17}$ To investigate the disordered structure of R-AC, Raman spectroscopy is widely used to determine the structural disorder that exists in carbonaceous materials. The Raman spectra in Fig. 1b display two prominent peaks at $1330 \mathrm{~cm}^{-1}$ and $1602 \mathrm{~cm}^{-1}$, which correspond to the $\mathrm{D}$ band ( $\mathrm{sp}^{3}$ carbon related to structural defects) and the $\mathrm{G}$ band $\left(\mathrm{sp}^{2}\right.$ carbon, which is the fingerprint of graphitic crystallites of carbon), respectively. The intensity ratio of these bands $\left(I_{\mathrm{D}} / I_{\mathrm{G}}\right)$ depends on the ratio of the concentrations of $\mathrm{sp}^{3}$ and $\mathrm{sp}^{2}$ carbons, which is related to the degree of graphitization and can be used to analyse defective structures produced by different contents of various $\mathrm{C}-\mathrm{N}-\mathrm{C}$ terminal bonds. ${ }^{18,19}$ In particular, the $I_{\mathrm{D}} / I_{\mathrm{G}}$ ratio for NH-AC is 1.39 , which is higher than those for R-AC (1.30) and N-AC (1.29). It is evident that disordered and defective sites are predominant in the carbon matrix
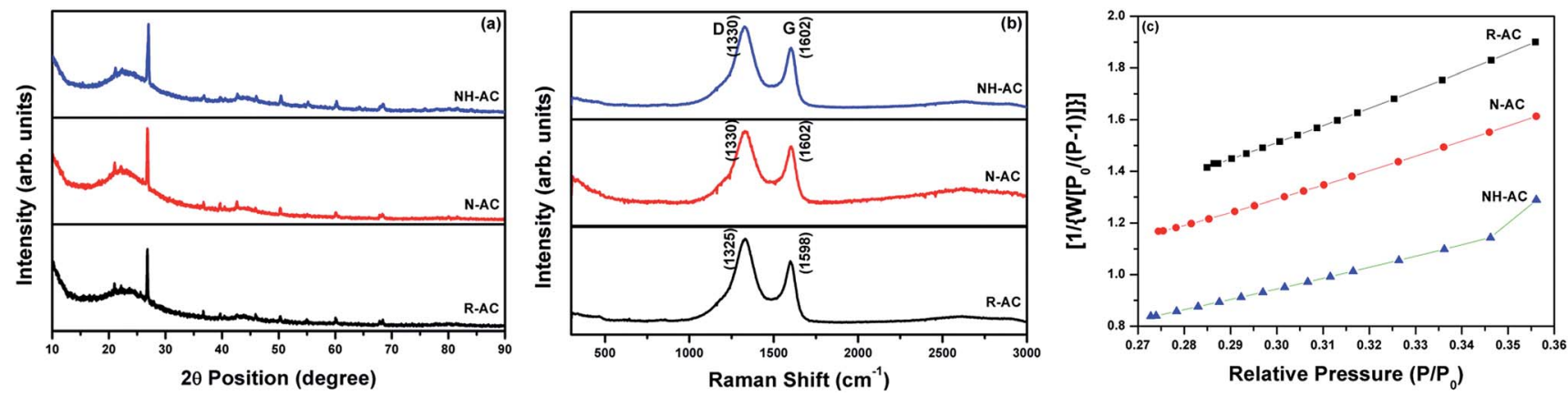

Fig. 1 (a) X-ray diffraction patterns, (b) Raman spectra and (c) surface area plots of unannealed activated carbon (R-AC) and activated carbon annealed under an $\mathrm{N}_{2}$ atmosphere $(\mathrm{N}-\mathrm{AC})$ and annealed under an $\mathrm{NH}_{3}$ atmosphere $(\mathrm{NH}-\mathrm{AC})$. 


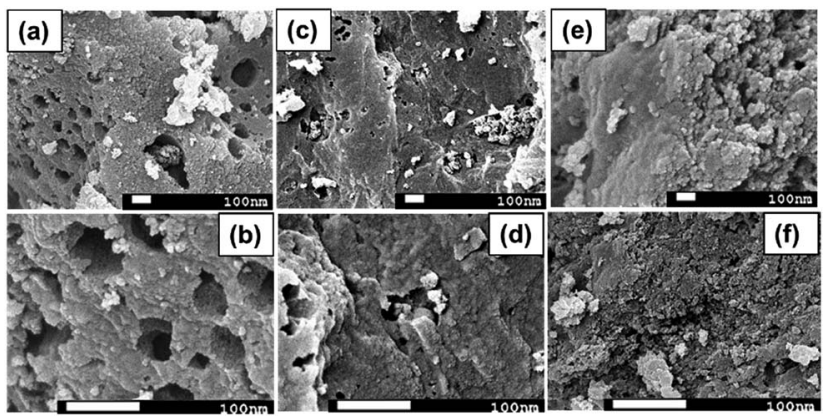

Fig. 2 Morphology of ( $a$ and b) raw activated charcoal (R-AC); (c and d) R-AC annealed under an $\mathrm{N}_{2}$ atmosphere (N-AC); (e and f) R-AC annealed under $\mathrm{NH}_{3}$ atmosphere $(\mathrm{NH}-\mathrm{AC})$.

of NH-AC owing to the introduction of heteroatoms during heat treatment under ammonia atmosphere. This is in good agreement with the conclusions drawn from the XRD pattern of $\mathrm{NH}^{-}$ AC. The larger electrolyte/electrode interfacial area will provide better wettability, as well as easy access to storage sites. Brunauer-Emmett-Teller (BET) measurements were conducted to determine the specific surface areas of all the samples. From the BET analysis, the measured specific surface areas were found to be $557,681.8$, and $894.5 \mathrm{~m}^{2} \mathrm{~g}^{-1}$ for R-AC, N-AC, and NH-AC, respectively, as shown in Fig. 1c. The increase in surface area for NH-AC was probably due to the removal of carbon from the surface by treatment with ammonia gas, which led to the formation of numerous micropores. ${ }^{20}$ This is clearly reflected in both the BET measurements and observations by field-emission scanning electron microscopy (FESEM) (Fig. 2).

Morphological investigations using scanning electron microscopy (SEM) were carried out for all samples (R-AC, N-AC, and NH-AC), and the SEM images are presented in Fig. 2. Fig. 2a and $\mathrm{b}$ show that R-AC contains numerous macropores. On annealing $\mathrm{R}-\mathrm{AC}$ under a nitrogen atmosphere for the preparation of N-AC (Fig. 2c and d), the nitrogen reacted with the surface of the carbon and removed oxygen in the form of CO and $\mathrm{CO}_{2}$ gases. The evolution of these gases will probably have created more pores, leading to a larger specific surface area. It is believed that the reaction between a carbon surface and gas molecules $\left(\mathrm{NH}_{3}\right)$ can lead to the substantial removal of carbon in the form of $\mathrm{CH}_{4}$. As a result, NH-AC (Fig. 2e and f) exhibits a larger specific surface area than that of N-AC and R-AC. ${ }^{20,21}$ It is evident from these SEM images that the porous structure was retained in all samples, even after annealing at $800{ }^{\circ} \mathrm{C}$.

X-ray photoelectron spectroscopy (XPS) analysis was performed to determine the elemental compositions and chemical states of the samples. The complete survey spectra of R-AC, N$\mathrm{AC}$, and NH-AC (not shown here) indicate that $\mathrm{C}$ and $\mathrm{O}$ elements are the major components, of which the peaks are centred at 284 and $532 \mathrm{eV}$, respectively, whereas the minor elements are $\mathrm{N}$ and Si. The elemental surface compositions of the samples are summarized in Table 1. It is observed from Table 1 that the nitrogen content increased with a decrease in the oxygen content when R-AC was annealed under both nitrogen and ammonia atmospheres. Moreover, from the $\mathrm{O} / \mathrm{C}$ ratio it is clear that the amount of polar functional groups
Table 1 Elemental surface composition of commercial activated charcoal and nitrogen-doped activated charcoal determined from XPS plots

\begin{tabular}{llllll}
\hline & \multicolumn{5}{c}{ Elemental composition (at\%) } \\
\cline { 2 - 5 } Sample ID & C 1s & N 1s & O 1s & Si 2p & O/C ratio \\
\hline R-AC & 64.3 & 2.6 & 32.5 & 0.6 & 0.51 \\
N-AC & 72.9 & 3.2 & 23.3 & 0.6 & 0.32 \\
NH-AC & 72.5 & 4.7 & 22.2 & 0.6 & 0.31 \\
\hline
\end{tabular}

was also drastically reduced during the heat treatment of R-AC. These polar functional groups were responsible for the formation of a thick and irregular SEI film on the surfaces of carbon particles. The high-resolution C 1s spectra of all the samples can be deconvolved into four peaks, as shown in Fig. 3a, c, and e. The peaks around 284.6, 285.5, 287, and $289.2 \mathrm{eV}$ can be assigned to $\mathrm{C}=\mathrm{C}, \mathrm{C}-\mathrm{N}$ and $\mathrm{C}-\mathrm{C}, \mathrm{C}=\mathrm{O}$, and $\mathrm{O}=\mathrm{C}-\mathrm{OH}$, respectively. Similarly, the high-resolution $\mathrm{N} 1 \mathrm{~s}$ spectra can be deconvolved into 4 peaks (Fig. 3b, d, and f); these are centred at 398.6, 400.1, 401.6, and $403.4 \mathrm{eV}$, which could be assigned to pyridinic $\mathrm{N}$, pyrrolic $\mathrm{N}$, graphitic $\mathrm{N}$, and oxidized $\mathrm{N}$, respectively. ${ }^{18,22-24}$ The doped nitrogen contents were found to be 2.6, 3.2 , and 4.7 at $\%$ for R-AC, N-AC, and NH-AC, respectively. From the point of view of electrochemical performance, a nitrogendoped carbon matrix (in particular with pyridinic $\mathrm{N}$ and pyrrolic N) could generate more active sites for lithium-ion
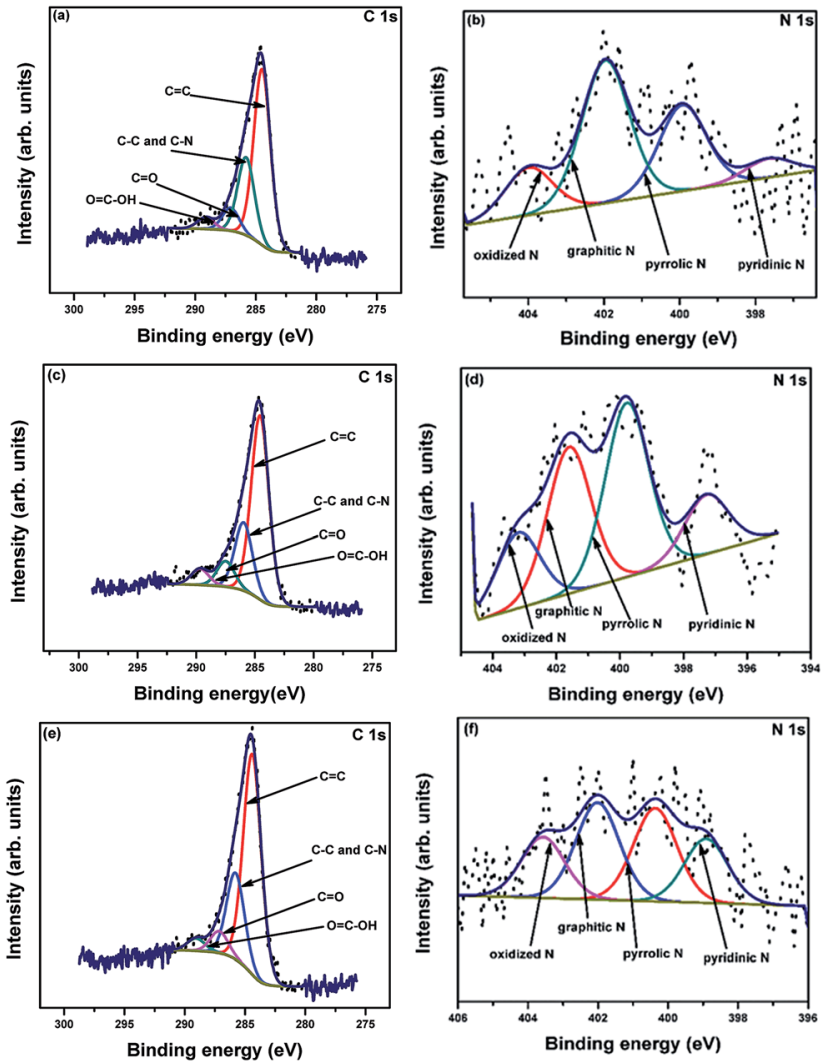

Fig. 3 XPS high-resolution $C 1$ s and $N$ 1s spectra of R-AC ( $a$ and $b$ ), N$A C$ (c and d), and $\mathrm{NH}-\mathrm{AC}$ (e and f). 
Table 2 Relative concentrations of different types of nitrogen calculated for the surface using $\mathrm{N}$ 1s spectra from XPS plots

\begin{tabular}{lllll}
\hline & \multicolumn{3}{l}{ Composition (at\%) } \\
\cline { 2 - 5 } & $\begin{array}{l}\text { Pyridinic N } \\
\text { Sample ID }\end{array}$ & $\begin{array}{l}\text { Pyrrolic N } \\
\text { 398.2 eV }\end{array}$ & $\begin{array}{l}\text { Graphitic N } \\
\text { O00.1 eV }\end{array}$ & $\begin{array}{l}\text { Oxidized N } \\
401.6 \mathrm{eV}\end{array}$ \\
\hline R-AC & 0.2 & 0.8 & 1.3 & 0.4 \\
N-AC & 0.4 & 1.2 & 1.0 & 0.5 \\
NH-AC & 1.0 & 1.4 & 1.4 & 0.9 \\
\hline
\end{tabular}

storage, as well as electron transport. A possible reason for the enhancement in electrochemical performance is the faradic reaction of the nitrogen-containing functional groups. ${ }^{\mathbf{1 8 2 2 - 2 4}}$ Furthermore, nitrogen doping also improved the wettability and conductivity of the carbon matrix. It is evident from Table 2 that the concentrations of pyridinic $\mathrm{N}$ and pyrrolic $\mathrm{N}$ are higher in NH-AC in comparison to those in R-AC and N-AC. The evolution of these functional groups in the NH-AC matrix increased the amount of pores, which is in good agreement with the BET analysis.

To acquire insights into the effects of $\mathrm{N}$ doping, commercial graphite, R-AC, N-AC, and $\mathrm{NH}-\mathrm{AC}$ were tested as anodes at a moderate current rate of $50 \mathrm{~mA} \mathrm{~g}^{-1}$. The initial specific discharge and charge capacities were found to be 402.3 and $284.1 \mathrm{~mA} \mathrm{~h} \mathrm{~g}^{-1}$ (graphite); 984.6 and $353.6 \mathrm{~mA} \mathrm{~h} \mathrm{~g}^{-1}$ (R-AC); 1165.3 and $482.9 \mathrm{~mA} \mathrm{~h} \mathrm{~g}{ }^{-1}$ (N-AC), and 2376.1 and 1092.6 $\mathrm{mA} \mathrm{h} \mathrm{g}^{-1}$ (NH-AC), respectively. The initial coulombic efficiency was greatly increased for NH-AC (45.98\%) in comparison that of to N-AC (41.44\%) and R-AC (35.91\%). This irreversible loss could be attributed to the irreversible formation of $\mathrm{Li}_{2} \mathrm{O}$ and the solid-electrolyte interphase (SEI), which retains lithium ions, and the decomposition of the electrolyte at lower voltages, as confirmed by CV (Fig. 4a, inset). This is in good agreement with other reports that refer to carbonaceous materials. ${ }^{\mathbf{8 , 1 0 , 1 3 , 1 6 , 2 1 , 2 5}}$ Nevertheless, all the electrodes exhibited a coulombic efficiency of $98-99 \%$ from the second cycle onwards. The NH-AC electrode delivered the highest reversible specific capacity of $736.4 \mathrm{~mA} \mathrm{~h}$ $\mathrm{g}^{-1}$ in comparison to $\mathrm{N}-\mathrm{AC}\left(464.9 \mathrm{~mA} \mathrm{~h} \mathrm{~g}^{-1}\right)$ and R-AC (459.9 $\mathrm{mA} \mathrm{h} \mathrm{g}^{-1}$ ) when the electrodes were cycled at a current rate of $50 \mathrm{~mA} \mathrm{~g}{ }^{-1}$, even after 150 cycles, which indicates superior performance to that of commercial graphite $\left(259.1 \mathrm{~mA} \mathrm{~h} \mathrm{~g}^{-1}\right)$, as shown in Fig. $4 \mathrm{~b}$ and $\mathrm{S} 2 . \dagger$

The voltage-specific discharge capacity profile can be divided into three regions (R-I, R-II, and R-III) according to the intercalation of $\mathrm{Li}^{+}$in different regions of carbon. ${ }^{26-28}$ Region R-I (0.002-0.1 V) can be mainly assigned to the intercalation of $\mathrm{Li}^{+}$ ions into the interplanar spaces between aligned graphene sheets. In the case of region R-II (0.1-0.9 V), the contribution to the specific capacity can be ascribed to the intercalation of $\mathrm{Li}^{+}$ between disordered and ordered graphene sheets. In the voltage

Table 3 Contributions to specific capacity in all regions of the voltage-specific capacity profiles of graphite, R-AC, N-AC, and $\mathrm{NH}$ AC

\begin{tabular}{lcrrr}
\hline & \multicolumn{4}{c}{ Specific capacity $\left(\mathrm{mA} \mathrm{h} \mathrm{g}^{-1}\right)$} \\
\cline { 2 - 5 } Region & Graphite & R-AC & N-AC & NH-AC \\
\hline R-I $(0.02-0.1 \mathrm{~V})$ & 216.1 & 148.4 & 257.5 & 563.5 \\
R-II $(0.1-0.9$ V) & 139.7 & 706.4 & 726.4 & 1435.5 \\
R-III (above 0.9 V) & 46.5 & 129.8 & 181.4 & 377.1 \\
Total specific capacity $\left(\mathrm{mA} \mathrm{h} \mathrm{g}^{-1}\right)$ & 402.3 & 984.6 & 1165.3 & 2376.1
\end{tabular}
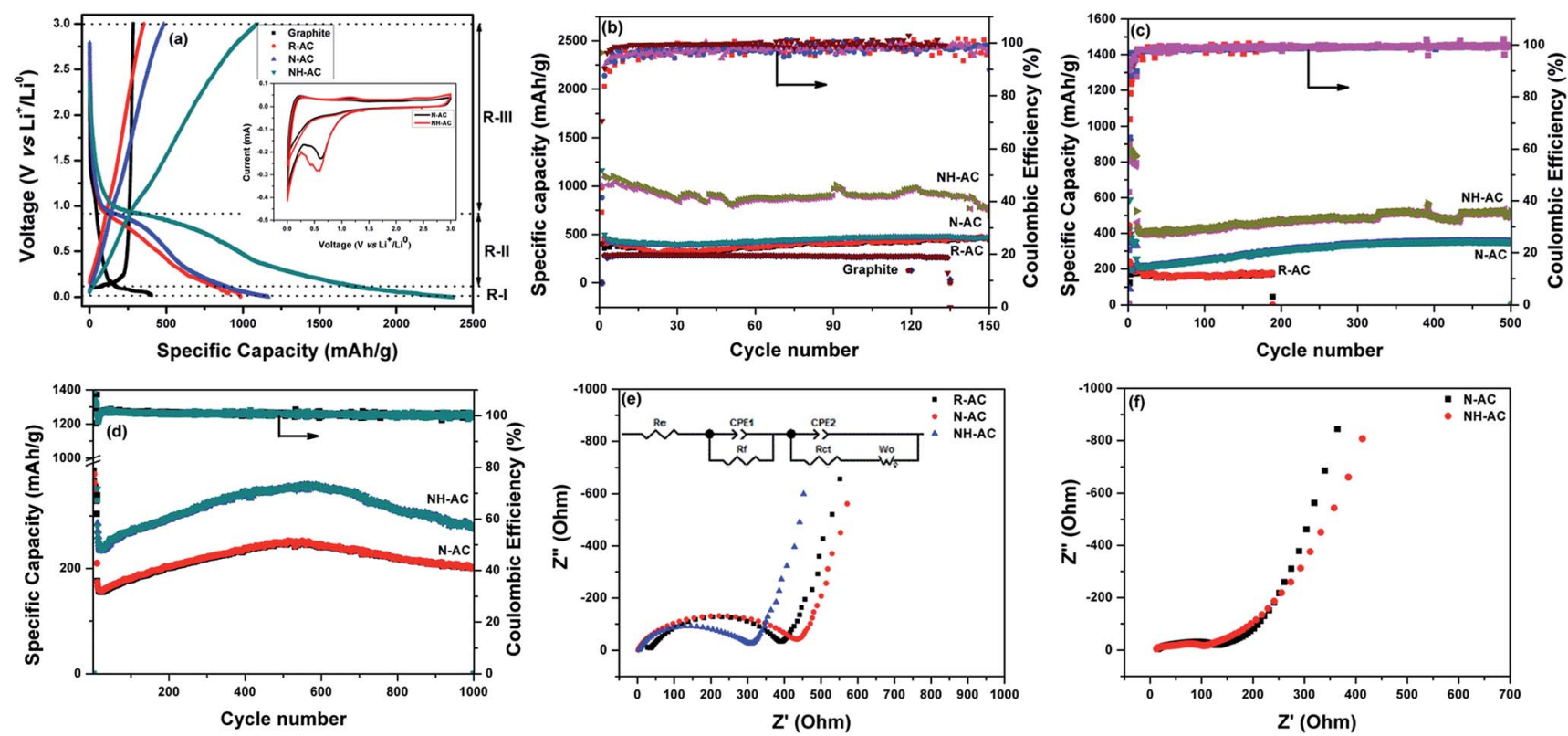

Fig. 4 Electrochemical performance of R-AC, $\mathrm{N}-\mathrm{AC}$, and $\mathrm{NH}-\mathrm{AC}$ : (a) first discharge-charge plots at $50 \mathrm{~mA} \mathrm{~g}^{-1}$ (with inset containing cyclic voltammograms of $\mathrm{N}-\mathrm{AC}$ and $\mathrm{NH}-\mathrm{AC}$ obtained at a scan rate of $0.1 \mathrm{mV} \mathrm{s}^{-1}$ for 3 cycles each); specific capacity plots at (b) $50 \mathrm{~mA} \mathrm{~g}^{-1}$, (c) 200 $\mathrm{mA} \mathrm{g}^{-1}$, and (d) $500 \mathrm{~mA} \mathrm{~g}^{-1}$; and impedance spectra and equivalent circuit (inset) of N-AC and NH-AC electrodes (e) before cycling and (f) after 1000 cycles. 


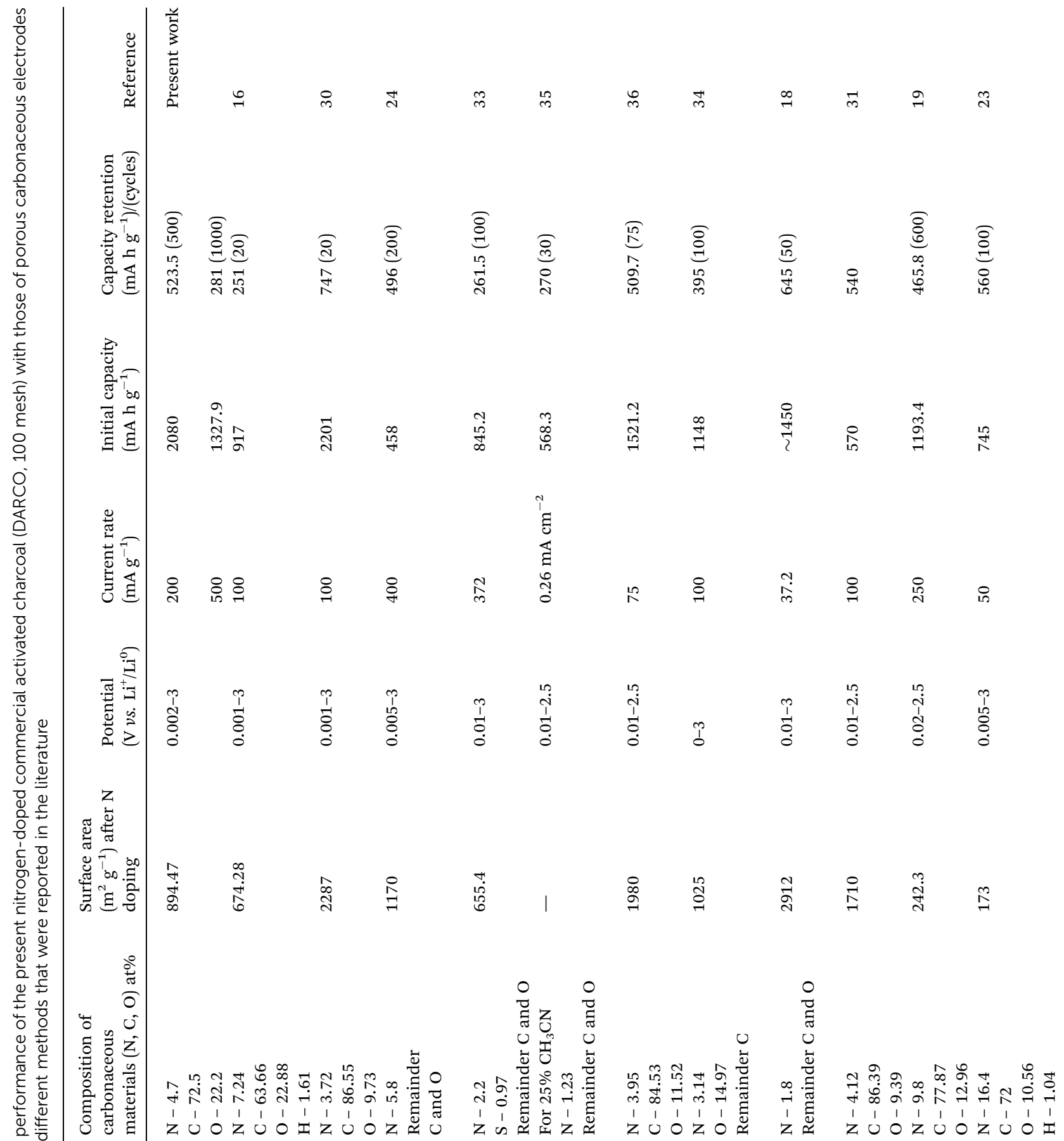

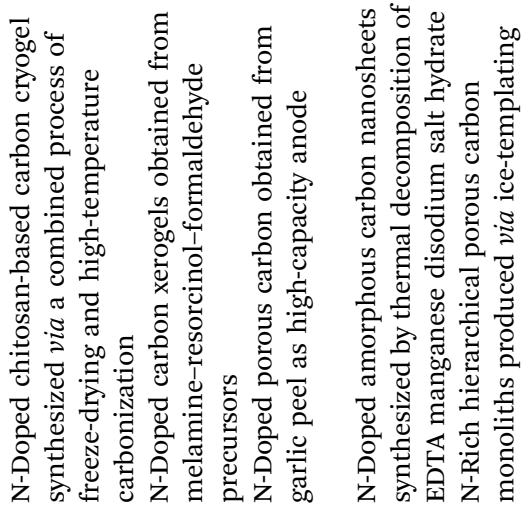




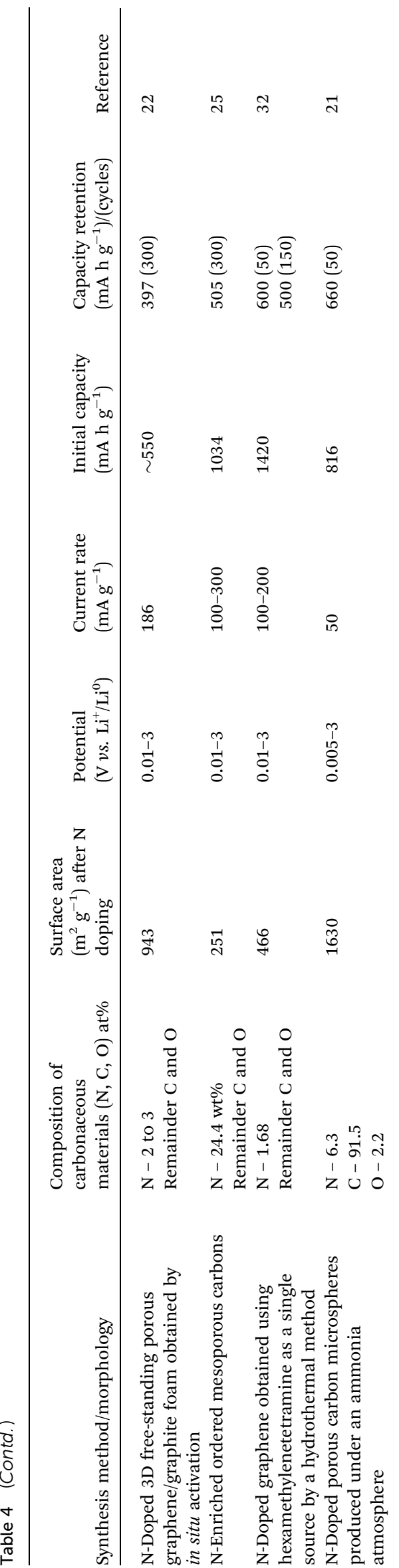

range above $0.9 \mathrm{~V}$ (R-III), the contribution to the capacity can be attributed to the intercalation of $\mathrm{Li}^{+}$into edge sites, in particular surface functional groups. Table 3 shows the contributions to the specific capacity for all regions of the profile.

As can be seen, in the case of graphite the contribution to the specific capacity mainly originates from the graphene sheets. $\mathrm{NH}-$ AC possesses higher specific capacity in the R-I region, which could be related to the number of available graphene sheets per unit area as well as the interplanar spacing between the graphene sheets, as confirmed by XRD. Furthermore, the increased specific capacity of NH-AC in the other regions (R-II and R-III) may be related to the disordered structure and surface functional groups, as confirmed by other characterization techniques such as XPS and Raman spectroscopy. Therefore, the contribution of the first cycle to the specific discharge capacity is correlated with the findings obtained from characterization techniques.

To test their long-term cycling stability at high current rates, NH-AC and N-AC were subjected to electrochemical performance testing at $200 \mathrm{~mA} \mathrm{~g}^{-1}$ for 500 cycles (Fig. 4c) and $500 \mathrm{~mA}$ $\mathrm{g}^{-1}$ for 1000 cycles (Fig. 4d) and rate capability testing at various current rates (Fig. S3†). NH-AC delivered high reversible capacities of $523.9 \mathrm{~mA} \mathrm{~h} \mathrm{~g}^{-1}$ and $281.1 \mathrm{~mA} \mathrm{~h} \mathrm{~g}^{-1}$ at current rates of 200 and $500 \mathrm{~mA} \mathrm{~g}^{-1}$ after 500 and 1000 cycles, respectively, whereas the N-AC electrode exhibited capacities of only 201.1 and $353 \mathrm{~mA} \mathrm{~h} \mathrm{~g}^{-1}$ at the same respective current rates and cycle numbers. It is believed that the intercalation of $\mathrm{Li}^{+}$into graphene sheets contributed to the discharge capacity when the potential was below $0.11 \mathrm{~V}$. Furthermore, the contribution of defects and surface functional groups to the capacity appeared above $0.1 \mathrm{~V} .{ }^{29}$ Therefore, carbon with a large surface area and a disordered graphite structure is preferred for accommodating a large quantity of lithium ions. Moreover, the specific surface area is beneficial for the adsorption of lithium ions at interfacial sites and reducing the overpotential (small charge transfer resistance) owing to a decrease in the local current density.

Fig. 4e shows the electrochemical impedance spectra of these electrodes, which provide further insights into their remarkable electrochemical performance. The Nyquist plots consist of a semicircle at high frequencies and a straight line at low frequencies, which are attributed to the electrolyte or solution resistance $\left(R_{\mathrm{e}}\right)$ offered at the electrode-electrolyte interface and the charge transfer resistance $\left(R_{\mathrm{ct}}\right)$ in the case of the semicircle and the Warburg diffusion $\left(W_{\mathrm{o}}\right)$ of lithium in the case of the straight line, together with a constant-phase element (CPE-1) and a non-ideal constant-phase element (CPE-2), as represented in the equivalent circuit model. N-AC and NH-AC displayed a negligible electrolyte resistance of $2.43 \Omega$ in comparison to $34.74 \Omega$ for R-AC, whereas NH-AC exhibited an initial $R_{\text {ct }}$ value of $306.85 \Omega$ in comparison to $431.52 \Omega$ for N-AC and $393.8 \Omega$ for R-AC. Therefore, the remarkable enhancement in Li storage for NH-AC can be considered to be due to (1) the high at $\% \mathrm{~N}$ content in the form of pyridinic $\mathrm{N}$ and pyrrolic $\mathrm{N}$, which increased the electronic conductivity and induced defects, creating new surface active sites that enhanced the reactivity of lithium; (2) the porous structure with a large surface area, which helped to accommodate the changes in volume during lithiation and delithiation; (3) the lowest solution/ 
electrolyte resistance at the electrode-electrolyte interface, which could further reduce the build-up of the SEI during cycling; and finally (4) the reduced $R_{\mathrm{ct}}$ value of NH-AC after 1000 cycles in comparison to that before cycling, which indicates that new sites were generated during cycling that promoted remarkably stable electrochemical performance, even after 1000 cycles at a high current rate of $500 \mathrm{~mA} \mathrm{~g}^{-1}$. The electrochemical performance of NH-AC was also compared with that of other reports in the literature, as shown in Table 4. This electrode's outstanding performance may be due to its increased nitrogen content ${ }^{18,30-34}$ and reduced $\mathrm{O} / \mathrm{C}$ ratio $^{16}$ and the solvent-free approach, which left no chemical residues to impede its electrochemical performance. ${ }^{\mathbf{1 6 , 1 8 , 1 9 , 2 4 , 3 3}}$ Thus, owing to its unique porous structure and low cost, $\mathrm{NH}-\mathrm{AC}$ is able to deliver excellent reversible specific capacity, high rate capability, and very good cycling stability, as well as shows great potential to be competitive with other next-generation anode materials for secondary rechargeable batteries.

\section{Conclusions}

In this study, a solvent-free approach was selected for doping nitrogen into commercial activated charcoal (R-AC) to demonstrate its potential as an anode for LIBs. For nitrogen doping, RAC was annealed under two different gases, namely, $\mathrm{N}_{2}$ (N-AC sample) and $\mathrm{NH}_{3}$ (NH-AC sample), and it was found for $\mathrm{NH}$ $\mathrm{AC}$ that the nitrogen content increased to 4.7 at\% in comparison to that of N-AC (3.2 at\%) and R-AC (2.6 at\%). Simultaneously, the specific surface area of NH-AC $\left(894.5 \mathrm{~m}^{2} \mathrm{~g}^{-1}\right)$ was increased together with a reduction in the $\mathrm{O} / \mathrm{C}$ ratio in comparison to the other samples. Upon testing against lithium, $\mathrm{NH}-\mathrm{AC}$ delivered remarkable specific capacities of $736.4 \mathrm{~mA} \mathrm{~h}$ $\mathrm{g}^{-1}$ after 150 cycles at $50 \mathrm{~mA} \mathrm{~g}^{-1}, 524 \mathrm{~mA} \mathrm{~h} \mathrm{~g}^{-1}$ after 500 cycles at $200 \mathrm{~mA} \mathrm{~g}^{-1}$, and a stable $281 \mathrm{~mA} \mathrm{~h} \mathrm{~g}^{-1}$ at $500 \mathrm{~mA} \mathrm{~g}^{-1}$, even after 1000 cycles, with improved reversible coulombic efficiency in comparison to commercial activated charcoal and other types of porous carbon, as shown in Table 4. This excellent electrochemical performance was achieved due to a reduction in electrolyte resistance, which restricted the build-up of the SEI, and the introduction of various $\mathrm{C}-\mathrm{N}-\mathrm{C}$ terminal bonds at induced defects and new active sites, which enhanced the reactivity of lithium, and therefore $\mathrm{NH}-\mathrm{AC}$ appears to be a promising candidate for high-performance lithium-ion batteries that require a high reversible specific capacity and remarkable cycling stability.

\section{Experimental}

\section{Materials synthesis}

Activated charcoal powder (R-AC) (DARCO, 100 mesh, product no. 242276, lot no. MKBJ9846V, Sigma-Aldrich) was used as the starting material. A sample of $1 \mathrm{~g}$ R-AC powder was taken in an alumina vial and placed inside a tubular furnace, which was then purged with nitrogen gas $\left(\mathrm{N}_{2}\right)$ for $1 \mathrm{~h}$ prior to the annealing process. The furnace temperature was maintained at $800{ }^{\circ} \mathrm{C}$ (ramped at $5{ }^{\circ} \mathrm{C} \min ^{-1}$ ) for $8 \mathrm{~h}$ and then cooled naturally to room temperature. The resulting product was denoted as N-AC.
The abovementioned procedure under similar conditions was carried out with another sample of $1 \mathrm{~g}$ R-AC under an ammonia gas atmosphere, and the product was denoted as NH-AC. All samples were preserved in a vacuum desiccator spread with silica gel to eliminate moisture.

\section{Materials characterizations}

Commercial raw activated charcoal (R-AC) and R-AC annealed in atmospheres of $\mathrm{N}_{2}$ (N-AC) and ammonia (NH-AC) gas were subjected to phase identification and surface and electrochemical characterization. X-ray diffraction (XRD, GBC MMA equipped with a $\mathrm{Cu} \mathrm{K}_{\alpha}$ radiation source) was employed for phase identification at a scan rate of $2^{\circ} \mathrm{min}^{-1}$ and a step size of $0.02^{\circ}$. Structural characterization of these materials was conducted by Raman spectroscopy using a Jobin Yvon Horiba Raman spectrometer (model HR800) with a $10 \mathrm{~mW}$ helium/ neon laser at an excitation wavelength of $632.8 \mathrm{~nm}$ in the range of $150-2000 \mathrm{~cm}^{-1}$. X-ray photoelectron spectroscopy (XPS) was conducted using a SPECS Phoibos 100 analyser installed in a high-vacuum chamber with a base pressure of less than $10^{-8}$ mbar, and X-ray excitation was provided by an $\mathrm{Al} \mathrm{K}_{\alpha}$ irradiation source with photon energy $h \nu$ of $1486.6 \mathrm{eV}$ at a high voltage of $12 \mathrm{kV}$ and a power of $120 \mathrm{~W}$. XPS binding energy spectra were recorded at a pass energy of $20 \mathrm{eV}$ in fixed analyser transmission mode, and data analysis was carried out using the CasaXPS 2.3.15 software package with all spectra calibrated against $\mathrm{C} 1 \mathrm{~s}=284.6 \mathrm{eV}$. Nitrogen adsorption-desorption studies were performed with a Quantachrome NOVA 1000 analyser for Brunauer-Emmett-Teller (BET) surface area analysis. Field-emission gun scanning electron microscopy (FEGSEM, JEOL JSM-7500F, Japan) was coupled with energydispersive X-ray spectroscopy (EDS) operated at $5 \mathrm{~V}$ and $10 \mu \mathrm{A}$ to visualize and study the structural morphologies and compositions of the samples.

\section{Electrochemical characterizations}

The electrochemical performance of the R-AC, N-AC, and NHAC samples was studied using CR2032 coin cells in a half-cell configuration, which were assembled in an argon-filled glove box (MBraun, Germany). All samples were blended individually with polyvinylidene fluoride (Sigma-Aldrich) as a binder in a weight ratio of $9: 1$, respectively, using $N$-methyl-2pyrrolidone as a solvent. The slurry was mixed using a planetary mixer (Kurabo Mazerustar, Japan), and the slurry that was obtained was tape-cast over the copper current collector using the doctor blade technique and vacuum-dried at $120{ }^{\circ} \mathrm{C}$ overnight. The dried electrodes were cut into circular discs, with each electrode loaded with $\sim 1 \mathrm{mg} \mathrm{cm}^{-2}$ active materials. The half-cell-type coin cells were assembled using the as-prepared electrodes as the working electrode with $\mathrm{Li}$ metal foil as the counter/reference electrode separated by Celgard polypropylene film as the separator, which was impregnated with a few drops of commercially available $1 \mathrm{M} \mathrm{LiPF}_{6}$ in a $1: 1(\mathrm{v} / \mathrm{v})$ mixture of ethylene carbonate (EC) and diethyl carbonate (DEC) as the electrolyte. All the assembled cells were electrochemically tested in a battery testing system (Land CT2001A, China) at a constant 
specific current rate $\left(\mathrm{mA} \mathrm{g}^{-1}\right)$ between 0.002 and 3.0 V. A Biologic VMP3 electrochemical workstation was employed to perform cyclic voltammetry $(\mathrm{CV})$ at a scan rate of $0.1 \mathrm{mV} \mathrm{s}^{-1}$ and potentiostatic electrochemical impedance spectroscopy (PEIS) in the frequency range of $0.1 \mathrm{MHz}$ to $10 \mathrm{mHz}$ against $\mathrm{Li}^{+} / \mathrm{Li}^{0}$.

\section{Acknowledgements}

The authors are grateful to the Commonwealth of Australia, Excellerate Australia, and the Automotive Australia 2020 Cooperative Research Centre (CRC) for financial support under project code AutoCRC 1-111, the Australian Research Council (ARC) for financial support through a Linkage Infrastructure Equipment and Facilities (LIEF) grant (No. LE0237478), with the facilities located at the UOW Electron Microscopy Centre, and the Institute for Superconducting and Electronic Materials (ISEM) for the use of its infrastructure as part of in-kind support. The authors would also like to thank Dr Tania Silver for critical review of the study. We also thank Yajie Liu and Dr Nasir Mahmood for Raman studies and technical discussions, respectively.

\section{References}

1 M. Armand and J. M. Tarascon, Nature, 2008, 451, 652-657.

2 J. B. Goodenough and Y. Kim, Chem. Mater., 2010, 22, 587603.

3 B. Dunn, H. Kamath and J.-M. Tarascon, Science, 2011, 334, 928.

4 A. Magasinski, P. Dixon, B. Hertzberg, A. Kvit, J. Ayala and G. Yushin, Nat. Mater., 2010, 9, 353-358.

5 P. G. Bruce, B. Scrosati and J.-M. Tarascon, Angew. Chem., Int. Ed., 2008, 47, 2930-2946.

6 C. M. E. Peled, D. Bar-Tow and A. Melman, J. Electrochem. Soc., 1996, 143, 4.

7 D. Aurbach, E. Zinigrad, Y. Cohen and H. Teller, Solid State Ionics, 2002, 148, 405-416.

8 R. A. Chunhui Chen, Y. Hao and C. Wang, ECS J. Solid State Sci. Technol., 2013, 2, 4.

9 E. Unur, S. Brutti, S. Panero and B. Scrosati, Microporous Mesoporous Mater., 2013, 174, 25-33.

10 K. Zhang, X. Li, J. Liang, Y. Zhu, L. Hu, Q. Cheng, C. Guo, N. Lin and Y. Qian, Electrochim. Acta, 2015, 155, 174-182.

11 W. Kiciński, M. Szala and M. Bystrzejewski, Carbon, 2014, 68, $1-32$.

12 J. P. Paraknowitsch and A. Thomas, Energy Environ. Sci., 2013, 6, 2839-2855.

13 H.-g. Wang, Z. Wu, F.-l. Meng, D.-l. Ma, X.-l. Huang, L.-m. Wang and X.-b. Zhang, ChemSusChem, 2013, 6, 56-60.

14 N. R. Srinivasan, P. A. Shankar and R. Bandyopadhyaya, Carbon, 2013, 57, 1-10.
15 A. Dandekar, R. T. K. Baker and M. A. Vannice, Carbon, 1998, 36, 1821-1831.

16 E. Liu, H. Shen, X. Xiang, Z. Huang, Y. Tian, Y. Wu, Z. Wu and H. Xie, Mater. Lett., 2012, 67, 390-393.

17 M. Sevilla and R. Mokaya, Energy Environ. Sci., 2014, 7, 12501280.

18 X. Liu, S. Li, J. Mei, W.-M. Lau, R. Mi, Y. Li, H. Liu and L. Liu, J. Mater. Chem. A, 2014, 2, 14429-14438.

19 W. Guo, X. Li, J. Xu, H. K. Liu, J. Ma and S. X. Dou, Electrochim. Acta, 2016, 188, 414-420.

20 K. Y. Kang, B. I. Lee and J. S. Lee, Carbon, 2009, 47, 11711180.

21 T. Chen, L. Pan, T. A. J. Loh, D. H. C. Chua, Y. Yao, Q. Chen, D. Li, W. Qin and Z. Sun, Dalton Trans., 2014, 43, 1493114935.

22 J. Ji, J. Liu, L. Lai, X. Zhao, Y. Zhen, J. Lin, Y. Zhu, H. Ji, L. L. Zhang and R. S. Ruoff, ACS Nano, 2015, 9, 8609-8616.

23 A. D. Roberts, S. Wang, X. Li and H. Zhang, J. Mater. Chem. A, 2014, 2, 17787-17796.

24 Z.-Y. Sui, C. Wang, Q.-S. Yang, K. Shu, Y.-W. Liu, B.-H. Han and G. G. Wallace, J. Mater. Chem. A, 2015, 3, 18229-18237.

25 J. Zhu, J. Yang, R. Miao, Z. Yao, X. Zhuang and X. Feng, J. Mater. Chem. A, 2016, 4, 2286-2292.

26 J. R. Dahn, A. K. Sleigh, H. Shi, J. N. Reimers, Q. Zhong and B. M. Way, Electrochim. Acta, 1993, 38, 1179-1191.

27 Y. Liu, J. S. Xue, T. Zheng and J. R. Dahn, Carbon, 1996, 34, 193-200.

28 U. v. S. a. J. R. D. Rosamaría Fong, J. Electrochem. Soc., 1990, 137, 5.

29 N. R. Srinivasan, S. Mitra and R. Bandyopadhyaya, Phys. Chem. Chem. Phys., 2014, 16, 6630-6640.

30 L. Li, E. Liu, Y. Yang, H. Shen, Z. Huang and X. Xiang, Mater. Lett., 2010, 64, 2115-2117.

31 V. Selvamani, R. Ravikumar, V. Suryanarayanan, D. Velayutham and S. Gopukumar, Electrochim. Acta, 2016, 190, 337-345.

32 Z. Xing, Z. Ju, Y. Zhao, J. Wan, Y. Zhu, Y. Qiang and Y. Qian, Sci. Rep., 2016, 6, 26146.

33 G. Xu, J. Han, B. Ding, P. Nie, J. Pan, H. Dou, H. Li and X. Zhang, Green Chem., 2015, 17, 1668-1674.

34 L. Zheng, Y. Chang, F. Xiaoming, L. Shaohong, Y. Juan, Z. Mengdi, W. Gang, X. Nan and Q. Jieshan, Nanotechnology, 2015, 26, 374003.

35 L. G. Bulusheva, A. V. Okotrub, A. G. Kurenya, H. Zhang, H. Zhang, X. Chen and H. Song, Carbon, 2011, 49, 40134023.

36 V. Selvamani, R. Ravikumar, V. Suryanarayanan, D. Velayutham and S. Gopukumar, Electrochim. Acta, 2015, 182, 1-10. 